\title{
Resfriamento rápido de pimentão amarelo com ar forçado
}

\author{
Forced-air pre-cooling of yellow bell pepper
}

Silvia Antoniali ${ }^{{ }^{*}}$ Paulo Ademar Martins Leal $^{\mathrm{II}}$ Ana Maria de Magalhães ${ }^{\mathrm{II}}$ Juliana Sanches $^{\mathrm{I}}$

\section{RESUMO}

No presente trabalho, determinou-se o tempo de resfriamento de pimentão amarelo 'Zarco HS' submetido ao resfriamento rápido com ar forçado, usando diferentes tipos de embalagens, bem como sua conservação pós-colheita por um período de 30 dias sob refrigeração a $5,1 \pm 0,2^{\circ} \mathrm{C}$ e UR de $98,6 \pm 0,3 \%$. A temperatura foi medida através de termopares na câmara, no evaporador, nos frutos e nas embalagens, num total de 48 termopares. Foram realizadas as análises: perda de massa, teor de umidade e índice de firmeza. O trabalho permitiu concluir que o resfriamento rápido com ar forçado mostrou-se adequado quando aplicado como uma tecnologia de conservação pós-colheita para pimentão amarelo 'Zarco HS', com uma redução da temperatura de ${ }^{7 / 8}$ do tempo de resfriamento em no máximo 56 minutos.

Palavras-chave: Capsicum annum L., temperatura, conservação, pós-colheita.

\section{ABSTRACT}

In the present research it was determined the cooling time of yellow Bell pepper 'Zarco HS' submitted to forced air cooling, using different types of packaging, as well its postharvest conservation under refrigeration at $5,1 \pm 0,2^{\circ} \mathrm{C}$ and $98,6 \pm 0,3 \%$ RH during a period of 30 days under. The temperature was measured by thermocouples in the chamber, the evaporator, fruit and packs for a total of 48 thermocouples. The analysis of mass loss, humidity content, and firmness index were realized. It was possible to conclude that the forced air cooling process it's a feasible technology for postharvest conservation of yellow bell pepper 'Zarco HS' reducing the temperature of $7 / 8$ cooling time to the maximum of 56 minutes.

Key words: Capsicum annum L., temperature, conservation, postharvest.

\section{INTRODUÇÃO}

O cultivo do pimentão (Capsicum annuum L.), no Brasil apresenta excelentes perspectivas de expansão, principalmente considerando-se os diferentes mercados que estão surgindo, pois, além de ser consumido fresco, tem sido processado industrialmente e está entre as 10 hortaliças mais consumidas no mercado brasileiro, com uma produção nacional de 248.767 toneladas, segundo o IBGE (2011). A região Sudeste participa com $48 \%$ da produção nacional de pimentão e o Estado de São Paulo é o maior produtor desta hortaliça com, em 2006, 48.585 toneladas, correspondentes a 19\% da produção nacional (IBGE, 2011).

A não aplicação de tecnologia de conservação pós-colheita pelos produtores implica menor renda proveniente da comercialização. O produtor recebe menos porque necessita comercializar rapidamente sua produção, pois não possui técnicas apropriadas para o prolongamento da vida de prateleira do seu produto e o consumidor, através da baixa oferta do produto, paga mais caro.

Com a mudança dos hábitos alimentares ocorridos no Brasil nos últimos anos e com maior exigência de qualidade por parte dos consumidores, há uma necessidade maior de uso da refrigeração, não somente para a manutenção da qualidade como também para a redução das perdas (MALGARIM et al., 2006).

'Centro de Engenharia e Automação, Instituto Agronômico (IAC), Agência Paulista de Tecnologia dos Agronegócios (APTA), CP 26, 13201-970, Jundiaí, SP, Brasil. E-mail: santoniali@iac.sp.gov.br. *Autor para correspondência.

"Faculdade de Engenharia Agrícola, Universidade Estadual de Campinas (UNICAMP), Campinas, SP, Brasil. 
A respiração destaca-se como o principal fenômeno fisiológico que influencia na conservação e na qualidade das frutas e hortaliças após a colheita. A baixa temperatura diminui a taxa respiratória, além de proporcionar metabolismo mais lento, aumentando o período de armazenamento e, consequentemente, a manutenção da qualidade pós-colheita por mais tempo (CHITARRA \& CHITARRA, 2005; TALBOT \& CHAU, 2002).

$\mathrm{O}$ resfriamento é, geralmente, considerado como a remoção do calor de produtos recém-colhidos, visando à manutenção do frescor e do aroma da précolheita. O termo resfriamento rápido implica a retirada do calor de campo antes do produto ser transportado, processado ou armazenado e, geralmente, é feito em curto período de tempo logo após a colheita. Entretanto, somente o resfriamento na câmara de armazenamento não é considerado um resfriamento rápido (ASHRAE, 2010).

Para realizar o resfriamento rápido depois da colheita, diversos métodos podem ser utilizados, dentre eles, o sistema que utiliza ar forçado. Segundo THOMPSON et al. (1998), todos os produtos frescos podem ser resfriados com ar forçado, mas esse processo é comumente mais usado para frutas frescas e flores de corte. De acordo com LADANIYA(2008), a realização do resfriamento rápido antes da armazenagem ajuda a minimizar a perda de peso, a deterioração e a manter a qualidade dos produtos. Dependendo do produto e da capacidade do ventilador, o método é quatro a dez vezes mais rápido que o resfriamento na câmara de armazenamento (BACHMANN \& EARLES, 2000; LADANIYA, 2008).

Uma embalagem adequada é aquela capaz de oferecer proteção suficiente ao produto, preservando-lhe as características de qualidade até o consumo final. Aárea efetiva de abertura de uma caixa é imprescindível para a eficiência do resfriamento, sendo esse um processo simultâneo de transferência de calor e massa, cuja eficiência depende do contato do meio de resfriamento com o produto, permitindo além da rápida diminuição da temperatura, a manutenção dela, durante o armazenamento e transporte frigorificado (CORTEZ et al., 2002; KADER, 2002). Recomenda-se o uso de embalagens que apresentem no mínimo uma área de abertura de 5 a $10 \%$, no sentido da entrada do fluxo de ar (TALBOT \& FLETCHER, 2002; TALBOT \& CHAU, 1991). Segundo FERRUA \& SINGH (2011), a estrutura e design de embalagens são ainda baseados, em grande parte, em técnicas empíricas e, em geral permanecem deficientes na promoção do resfriamento rápido, uniforme e eficiente em termos energéticos. Esses mesmos autores afirmam que, ao aumentar a área de ventilação nas paredes de entrada e saída de ar das embalagens em
$35 \%$ e $19 \%$, respectivamente, a taxa de resfriamento dentro do sistema é reforçada.

Dentro desse contexto, o objetivo deste trabalho foi determinar o tempo de resfriamento de pimentão amarelo 'Zarco HS' submetido ao resfriamento rápido com ar forçado, acondicionado em diferentes tipos de embalagens, bem como sua conservação pós-colheita.

\section{MATERIAL E MÉTODOS}

Montagem experimental: o sistema de ar forçado foi montado dentro de câmara frigorífica. Utilizaram-se um conjunto moto-ventilador pressurizador e sistema de lona para vedar a região não utilizada da “janela”. O conjunto moto-ventilador é composto por ventilador centrífugo de dupla aspiração, linha leve, modelo BDC 381-286, vazão de ar de $4870 \mathrm{~m}^{3} \mathrm{~h}^{-1}$, pressão estática $10 \mathrm{mmCA}$, 535rpm, velocidade de $9,0 \mathrm{~m} \mathrm{~s}^{-1}$ e motor acoplado de $0,75 \mathrm{CV}$ trifásico $-220 \mathrm{~V}-60 \mathrm{~Hz}$. O ventilador succiona o ar refrigerado que sai do evaporador e o ar resfriado é forçado a passar transversalmente entre o volume das caixas com o produto colocadas no túnel de resfriamento, o qual está fechado na parte superior e frontal com uma lona. Para o monitoramento da temperatura, foi utilizado um sistema de aquisição de dados por computador, o qual é composto por um conversor de sinais A/D, uma placa de condicionamento de sinais e um computador. A temperatura do ar resfriado foi medida e monitorada usando para este fim um termopar colocado no interior da câmara de resfriamento. Para a medição da umidade relativa do ar, foram utilizados termopares de bulbo seco e bulbo úmido, através de um psicrômetro aspirado instalado no interior da câmara. Para cada embalagem, foram inseridos termopares de agulha (no interior do produto e no mesocarpo) e termopares na embalagem entre os frutos. Foi escolhido um fruto aleatório dentro de cada embalagem para medição da temperatura. Os pimentões amarelos 'Zarco HS' foram colhidos na manhã do dia da instalação do experimento e transportados, rapidamente, para o laboratório. Os pimentões amarelos foram selecionados através da coloração na faixa de 30 a $50 \%$ de cor amarela antes de serem acondicionados nas embalagens. Foram utilizadas no experimento seis caixas plásticas e seis caixas de papelão. A caixa plástica (capacidade: 6,5kg, dimensões 50x30x23cm) utilizada para acondicionamento do produto foi desenvolvida pela EMBRAPA HORTALIÇAS para comercialização de tomate e pimentão. Esta embalagem permite comportar pequeno número de camadas de produtos, possui superfície lisa e dispositivos de encaixe para 
empilhamento, não tem tampa e tem os cantos arredondados internamente para manter íntegra a casca do tomate e do pimentão. Para aplicação do resfriamento com ar forçado, foi necessário fazer uma pequena modificação na embalagem utilizada, porque esta possui um rebaixamento lateral acentuado, o qual possibilitaria a passagem do ar com maior facilidade, prejudicando o resfriamento do produto. Com isso, foi necessário o fechamento desta área de abertura na fase de entrada do ar, forçando-o a passar pelo produto e promover o resfriamento. Esta vedação foi realizada com fita adesiva transparente, aplicada somente na abertura indesejada, permanecendo ainda com uma área de abertura na face de entrada do ar de 12,7\%.

Em relação às embalagens de papelão (capacidade: 5kg, dimensões 47,7x27,6x13,6cm), através de avaliação junto à empresa RIGESA, das embalagens de papelão atualmente utilizadas para a comercialização de oleráceas, verificou-se a impossibilidade da aplicação do resfriamento rápido com ar forçado, pois as embalagens apresentavam área de abertura insuficiente na face de entrada do ar ou eram completamente desprovidas de qualquer área. Juntamente com os técnicos da empresa RIGESA, redimensionou-se uma destas embalagens visando ao resfriamento rápido com ar forçado, com área de abertura na face de entrada do ar de 5,22\%, valor recomendado para aplicação do resfriamento com ar forçado em embalagens de papelão. Para a coleta dos dados experimentais, foi aplicado um delineamento estatístico inteiramente casualizado para a avaliação do $7 / 8$ do tempo de resfriamento e, para cada embalagem utilizada, foram feitas seis repetições. Os resultados foram submetidos à análise de variância (ANOVA) e as médias comparadas pelo Teste de Tukey $(\mathrm{P} \leq 0,01)$.

Determinação do tempo de resfriamento: para a determinação do tempo de resfriamento, foram utilizados os dados de temperatura, lidos no interior e no mesocarpo do pimentão amarelo. Com a temperatura de cada ponto monitorada, foi calculado o tempo dos sete oitavos do resfriamento, ou seja, o tempo necessário para reduzir a $1 / 8$ a diferença entre a temperatura inicial do produto e do meio de resfriamento. $\mathrm{O}$ sistema foi programado para trabalhar a uma temperatura de $6,8 \pm 0,6^{\circ} \mathrm{C}$ para garantir um resfriamento rápido dos pimentões amarelos. A temperatura média do produto no início dos experimentos foi de $23,4 \pm 1,9^{\circ} \mathrm{C}$. Para as condições experimentais, 0 $7 / 8$ do tempo de resfriamento seria atingido quando a temperatura monitorada fosse de aproximadamente $8,9^{\circ} \mathrm{C}$. O sistema de aquisição de dados foi programado para monitorar as leituras de temperatura com uma frequência de 30 segundos durante todo o tempo em que o sistema se manteve ligado. Os dados experimentais foram processados com o auxílio de uma planilha do Office Excel (Versão: 972003, Microsoft, Brasil). Após o resfriamento rápido do pimentão amarelo com ar forçado, as caixas com os produtos foram mantidas na mesma câmara frigorífica, dispostas em prateleiras para avaliar a qualidade do pimentão amarelo armazenado por 30 dias sob refrigeração a $5,1 \pm 0,2^{\circ} \mathrm{C}$ e UR de $98,6 \pm 0,3 \%$. O sistema de aquisição de dados foi novamente reiniciado para monitoramento da temperatura no decorrer da estocagem.

Avaliações físicas: as avaliações físicas da qualidade do pimentão amarelo armazenado por 30 dias sob refrigeração a $5,1 \pm 0,2^{\circ} \mathrm{C}$ e UR de $98,6 \pm 0,3 \%$ foram realizadas através dos seguintes parâmetros: perda de massa fresca - aleatoriamente 02 frutos de cada caixa compuseram o grupo controle de peso. Antes do início do resfriamento rápido com ar forçado e no final período de armazenagem, estes foram pesados em balança semianalítica digital, Shimadzu, BL3200H. Os resultados foram expressos em porcentagem de perda de massa. Para o teor de umidade, foi realizada uma análise inicial e, no final do período de armazenagem, foi determinada tomando-se cerca de $5 \mathrm{~g}$ de cada repetição, cortado em pedaços e seco em estufa FANEN, 320SE, com circulação forçada de ar a $70^{\circ} \mathrm{C}$, até peso constante. Os resultados foram expressos em porcentagem na base úmida. A análise de resistência à compressão foi realizada no início e fim do experimento, seguindo o seguinte procedimento: retiraram-se espécimes cilíndricos do pericarpo do pimentão amarelo utilizando anel vazador. Cada espécime foi colocado na prensa mecânica - Canners Machinery Limited - ALPHA Instruments Model 1804C - na direção do eixo central, a prensa deslocou-se com uma taxa de deformação constante de $04 \mathrm{~mm} \mathrm{~min}^{-1}$ até a ruptura do espécime. Os dados foram obtidos através de um conversor automático de dados A-D - SPIDER 8, HBM Hottinger Baldwin Messtechnik e armazenados em computador. As amostras foram comprimidas imediatamente após o corte. Para os resultados, foi calculada a área formada pela força (N) e deformação (mm) a 40\% para todas as amostras e expressa em energia $(\mathrm{N} \cdot \mathrm{mm})$, sendo considerado como o índice de firmeza para o pimentão amarelo e o módulo de elasticidade através da curva de força $(\mathrm{N})$ por deformação $(\mathrm{mm})$. Escolhendo-se dois pontos na primeira parte linear da curva e com os valores de P1 (x1 e y1), P2 (x2 e y2) e os valores obtidos anteriormente da área, calculada a partir do diâmetro (A) e da espessura (h) de cada espécime, encontrou-se o índice de deformação, representado pelo módulo de elasticidade do produto, (E em MPA) pela Equação 1. O delineamento estatístico utilizado 
para as avaliações físicas foi o inteiramente casualizado com 12 repetições por tipo de embalagem e, para verificação da diferença significativa entre as médias, foi utilizado o teste de Tukey $(\mathrm{P}<0,05)$.

$$
E=\frac{\frac{y 2-y 1}{A}}{\frac{x 2-x 1}{h}}
$$

Equação 1 - Equação para determinação do índice de firmeza através do módulo de elasticidade.

\section{RESULTADOS E DISCUSSÃO}

Avaliação do $7 / 8$ do tempo de resfriamento: para os pimentões resfriados com ar forçado, verificase na figura 1 que o tempo de resfriamento variou entre 26,5 e 56 minutos até que os pimentões atingissem a temperatura de $7 / 8$ do tempo de resfriamento, sendo que a primeira a resfriar foi a polpa do produto embalado na caixa plástica e a última a polpa do pimentão embalado na caixa de papelão, devido a diferença nas percentagens de abertura na face de entrada do ar frio (plástica com $12 \%$ e papelão com $5 \%$ ). O ar interno do produto embalado na caixa de papelão apresentou um $7 / 8$ do tempo de resfriamento menor que a polpa. Isso provavelmente ocorreu devido ao ponto de inserção dos termopares que, possivelmente, ficaram afastados das áreas de aberturas ou em local com um menor fluxo de ar frio, retardando a leitura do resfriamento. A temperatura da câmara se manteve em média a $6,8 \pm 0,6^{\circ} \mathrm{C}$. Segundo ELANSARI (2008), o tempo necessário para reduzir a temperatura até $7 / 8$ é independente da temperatura inicial do produto. BROSNAN \& SUN (2001) relatam que, se, em duas horas, a temperatura é reduzida em $50 \%$ da temperatura inicial, em mais duas horas, esta será reduzida até $25 \%$ e assim sucessivamente, formando, portanto, uma curva exponencial de redução da temperatura (Figura 1). A mesma curva exponencial foi encontrada por BRACKMANN et al. (2009), quando resfriaram pêssegos em água gelada ou ar forçado. Usando a análise de variância, verificou-se que houve diferença significativa em nível de $1 \%$ de probabilidade entre as embalagens estudadas $\left(\mathrm{F}_{\text {Tab. } 0,01 ; 3 ; 20}=4,94<\mathrm{F}_{\text {Calc. }}=14,40\right)$. A embalagem plástica, por apresentar uma maior área de abertura na face de entrada do ar frio, proporcionou um $7 / 8$ do tempo de resfriamento menor que a embalagem de papelão. Deve-se ressaltar que houve necessidade de vedação da abertura indesejável que a caixa plástica apresentava. Assim, pode-se afirmar que, quanto maior a percentagem de área de abertura na face de entrada do ar frio, menor será 0 \% $/ 8$ do tempo de resfriamento, corroborando os dados de VISSOTTO et al. (2000). Da mesma forma, TERUEL et al. (2002) relatam que, quando a embalagem apresenta menor área para a passagem do ar, o tempo de resfriamento pode ser até 45\% maior. Portanto, uma embalagem com área de abertura inadequada para a realização do resfriamento

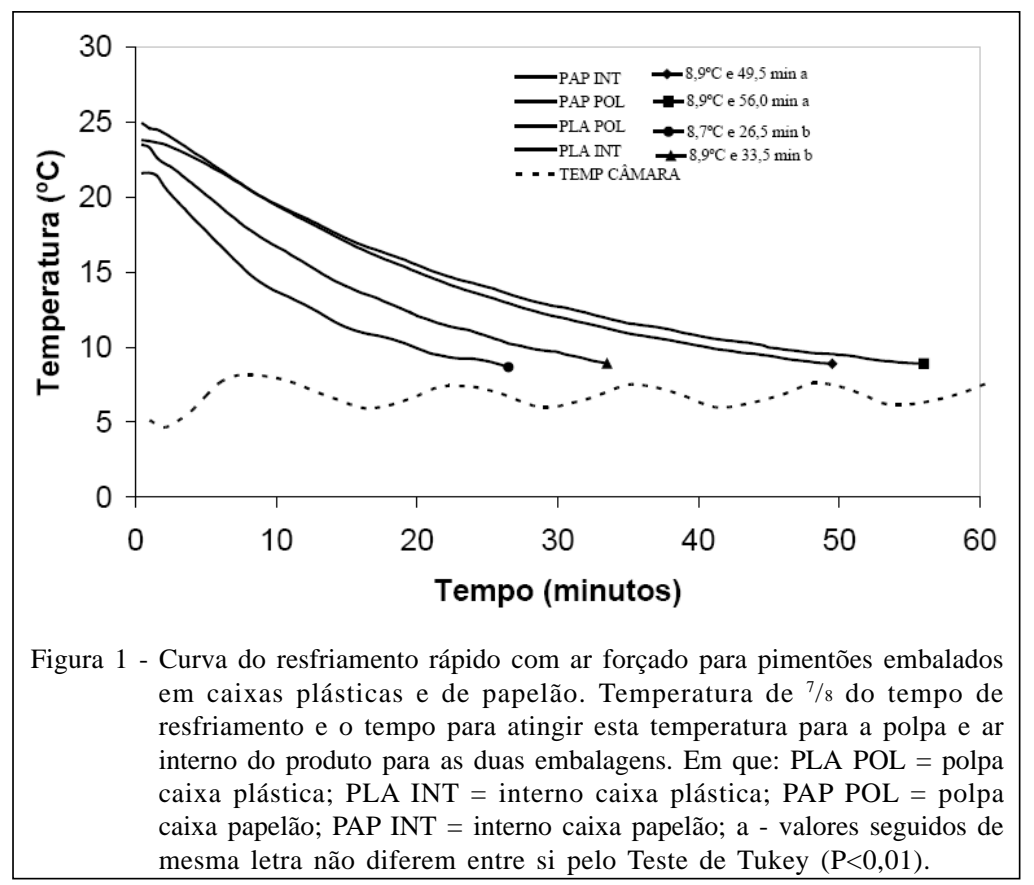

Ciência Rural, v.42, n.6, jun, 2012. 
rápido com ar forçado irá impedir que o ar frio se desloque corretamente entre o produto, prejudicando o processo de resfriamento. Segundo esses mesmos autores, a taxa de ar, que está diretamente relacionada com a velocidade do fluxo de ar e o tipo de embalagem, mostrou exercer uma influência significativa no tempo de resfriamento. Quando se compararam os dois pontos de leitura da temperatura no produto, verificou-se que, para a mesma embalagem, não houve diferença significativa (Figura 1). Ao longo do período de armazenagem, a temperatura manteve-se constante e a temperatura média da câmara frigorífica foi de $5,1 \pm 0,2^{\circ} \mathrm{C}$ e UR de $98,6 \pm 0,3 \%$; a temperatura do ar na caixa plástica foi de $4,8 \pm 0,25^{\circ} \mathrm{C}$ e a temperatura do ar na caixa de papelão foi de $5,7 \pm 0,11^{\circ} \mathrm{C}$. Para o teor de umidade do produto no primeiro e no trigésimo dia (armazenado a $5,1 \pm 0,2^{\circ} \mathrm{C}$ e UR de $98,6 \pm 0,3 \%$ ), observa-se, na figura $2 \mathrm{~A}$, que esta característica física apresentou uma redução de 13,8\% para os produtos acondicionados em caixa plástica e 13,9\% para os da caixa de papelão. Mesmo com esta redução no teor de umidade, o produto não apresentou sintomas visíveis de murcha após 30 dias de armazenamento. Quando se observa o pericarpo do pimentão amarelo, nota-se que o endocarpo não possui a cutícula protetora presente no epicarpo, que reduz a perda de água por transpiração para o meio externo. Verificou-se que ocorreu uma transferência de massa do endocarpo, por meio de transpiração, para a cavidade interna do pimentão, que é oca. A água ficou retida no interior do fruto, impossibilitando que a perda de massa fosse corretamente detectada. $\mathrm{Na}$ análise de teor de umidade, devido ao corte do fruto e secagem em estufa com ar forçado, foi possível verificar a perda de massa que ocorreu durante o período de armazenamento. Quanto as duas embalagens estudadas, verificou-se que ambas interferiram igualmente na redução do teor de umidade para o produto em estudo. Na figura 2B, observase que a perda de massa atingiu $5,22 \%$ para a caixa plástica e 5,34\% para a caixa de papelão, após 30 dias de armazenamento, apresentando praticamente a mesma evolução. Isso se confirma quando ambas são submetidas à análise de variância $\left(\mathrm{F}_{\text {Tab.; 0,05; 1; 22 }}=4,30>\mathrm{F}_{\text {Calc. }}=0,03\right)$, na qual é determinada a não diferença significativa em nível de $5 \%$ de probabilidade para os dois tratamentos, podendo-se verificar que as embalagens estudadas interferiram igualmente na perda de massa dos pimentões amarelos armazenados sob refrigeração por 30 dias. A porcentagem de perda de massa encontrada foi inferior ao relatado por MEDINA (1984), quando afirma que o pimentão pode perder cerca de $6,1 \%$ do seu peso sem mostrar sintomas de murcha e perda de qualidade. $\mathrm{O}$ índice de firmeza do pimentão amarelo,

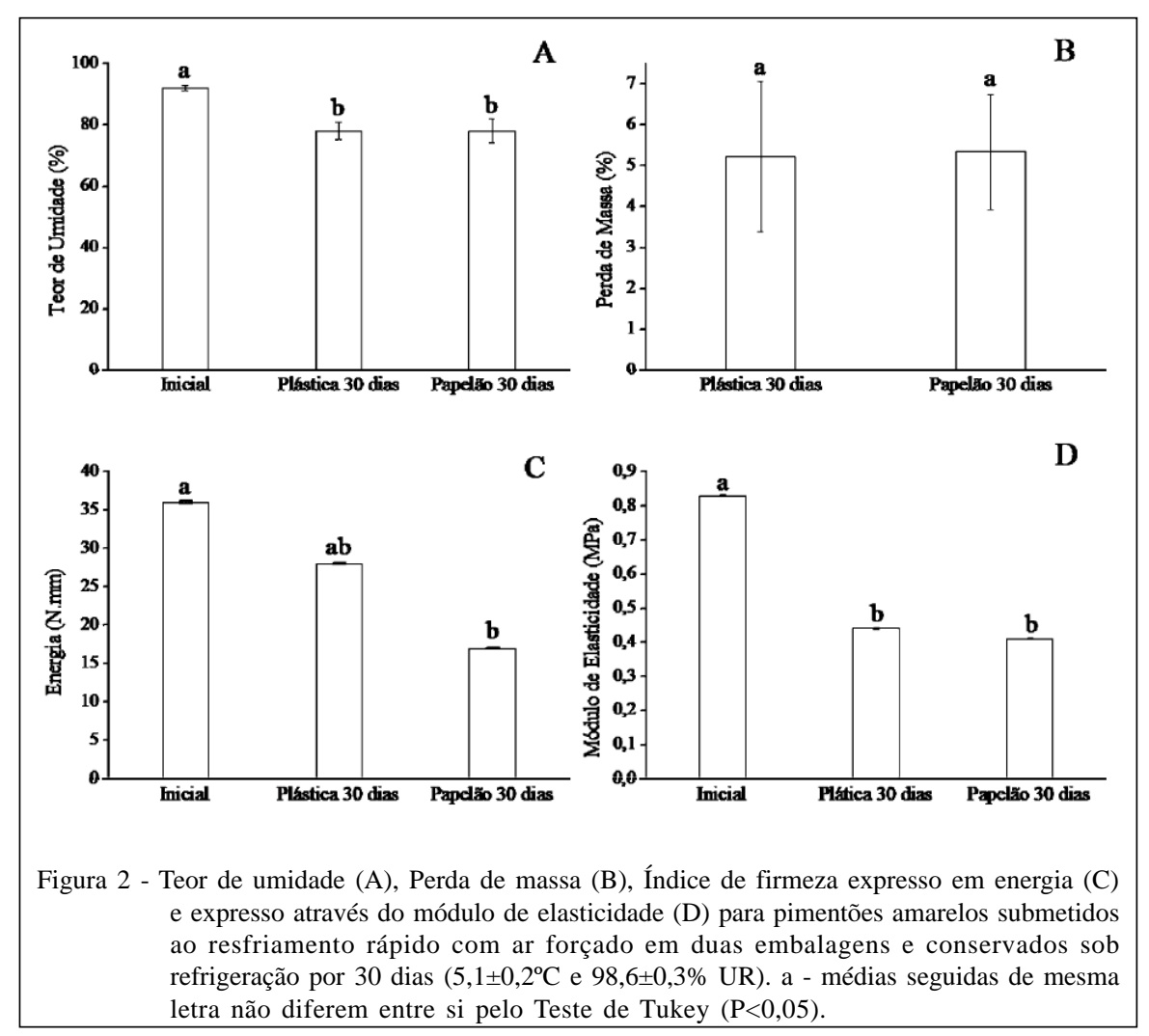

Ciência Rural, v.42, n.6, jun, 2012. 
expresso em energia (Figura 2C), também decresceu durante o período de armazenamento. Para os produtos embalados na caixa de papelão, o índice de firmeza foi estatisticamente inferior ao do produto no primeiro dia, indicando que, à medida que o produto amadurece, com perda de massa e teor de umidade, o pericarpo se torna menos rígido e menos tenro. A parede celular é um dos principais determinantes das propriedades mecânicas do tecido vegetal. Na polpa de frutos, a parede celular é composta principalmente por celulose, hemicelulose e pectina (WHITNEY et al., 1999). Durante o amadurecimento, parte da pectina e da hemicelulose são hidrolisadas, tendo como resultado o amolecimento do fruto (PRASANNA et al., 2007). Quando se analisou o índice de firmeza através do módulo de elasticidade (Figura 2D), verificou-se que os pimentões amarelos apresentaram perda neste parâmetro, em relação ao inicial, independentemente da embalagem estudada. Em relação às duas metodologias utilizadas para avaliar o índice de firmeza do produto, nas condições experimentais, a avaliação através do módulo de elasticidade apresentou-se com resultados mais consistentes na comparação dos sistemas utilizados, devido à maior clareza na apresentação e interpretação dos dados coletados.

\section{CONCLUSÃO}

O resfriamento rápido com ar forçado mostrouse adequado quando aplicado como uma tecnologia de conservação pós-colheita para pimentão amarelo 'Zarco HS', com uma redução da temperatura de $7 / 8$ do tempo de resfriamento em no máximo 56 minutos.

As embalagens de papelão e plástico estudadas apresentaram-se favoráveis para conservação pós-colheita de pimentão amarelo submetido ao resfriamento rápido com ar forçado e conservado por 30 dias.

A embalagem plástica, por apresentar maior área de abertura na fase de entrada do ar frio, mostrouse mais apropriada que a de papelão para aplicação desta tecnologia em pimentões amarelos.

No caso do pimentão amarelo, resfriado rapidamente com ar forçado e conservado a $5^{\circ} \mathrm{C}$ por 30 dias, embora com redução da firmeza e teor de umidade e aumento da perda de massa fresca, essas alterações não foram suficientes para afetar a qualidade do produto durante este período.

\section{AGRADECIMENTOS}

À Fundação de Amparo à Pesquisa do Estado de São Paulo (FAPESP), pelo financiamento do projeto (99/
04969-7), ao Serviço de Apoio ao Estudante (SAE) e Programa Institucional de Bolsas de Iniciação Científica (PIBIC), pela concessão das bolsas de iniciação científica, ao Conselho Nacional de Desenvolvimento Científico e Tecnológico (CNPq), pela concessão da bolsa de doutorado e à Empresa Rigesa, pelo fornecimento das caixas de papelão.

\section{REFERÊNCIAS}

ASHRAE HANDBOOK. Methods of precooling fruits, vegetables, and cut flowers. In: __ Refrigeration systems and applications. Atlanta: SI Edition, 2010. Cap.28, p.1-10.

BACHMANN, J.; EARLES, R.A. Postharvest handling of fruits and vegetables. Horticulture technical note. Appropriate technology transfer for rural areas. Washington: ATTRA Publication, 2000. 19p. Disponível em: <http:// attra.ncat.org/attar-pub/PDF/postharvest.pdf $>$. Acesso em: 07 abr. 2011.

BRACKMANN, A. et al. Pré-resfriamento sobre a qualidade de pêssegos 'Chiripá'. Ciência Rural, Santa Maria, v.39, n.8, p.2354-2360, 2009. Disponível em: <http://www.scielo.br/ s cielo.php? s c ript = s ci_art text \& pid=S 0103 84782009000800013\&lng=pt\&nrm=iso $>$. Acesso em: 08 abr. 2011. doi: 10.1590/S0103-84782009005000192.

BROSNAN, T.; SUN, D.W. Precooling techniques and applications for horticultural products - a review. International Journal of Refrigeration, Oxford, v.24, p.154-170, 2001. Disponível em: <http://www.sciencedirect.com/ science?_ob=ArticleURL\&_udi=B6V4R-428115S$5 \&$ user $=5477862 \&$ coverDate $=03 \% 2 \mathrm{~F} 31 \% 2 \mathrm{~F} 2001 \&$ alid $=$ $1710909817 \&$ \&doc=1\&_fmt $=$ high \&_orig=search \&_origin=search\&_zone=rslt_list_item \&_cdi $=5765 \&$ _ sort $=r \& \_s t=13 \& \_$docanchor $=\&$ view $=$ c\&_ct $=1 \&$ \& acct $=\bar{C}$ $000067456 \&$ _version $=1 \&$ urlVersion $=0 \&$ userid $=5477862 \& m d 5$ $=4 \mathrm{~b} 23842 \mathrm{acd} 3264 \mathrm{~d} 459 \mathrm{~cd} 3311 \mathrm{a} 5 \mathrm{f} 9160 \mathrm{~b} \&$ searchtype $=\mathrm{a}>$. Aces so em: 08 abr. 2011. doi: 10.1016/S0140-7007(00)00017-7.

CHITARRA, M.I.F.; CHITARRA, A.B. Pós-colheita de frutas e hortaliças - Fisiologia e manuseio. Lavras: UFLA, 2005. 783p.

CORTEZ, L.A.B. et al. Resfriamento de frutas e hortaliças. Brasília: Embrapa Hortaliças, 2002. 428p.

ELANSARI, A.M. Hydrocooling rates of Barhee dates at the Khalal stage. Postharvest Biology and Technology, Amsterdam, v.48, p.402-407, 2008. Disponível em: <http:// www.sciencedirect.com/science?_ob=ArticleURL\&_udi= B6TBJ-4S02D6G-1\&_user $=5477862 \&$ _coverDate $=$ 06\%2F30\%2F2008\&_alid=171 1056033\&_rdoc $=1 \&$ fmt $=$ h i g h \&_orig = s e a r c h \&_orig i n = s e a r c h \&_zone=rslt_list_item \&_cdi $=5144 \&$ \&t $=13 \&$ \&docanchor $=\&$ view $=$ c \&_ct $=1 \&$ \& acct $=\mathrm{C} 000067456 \&$ \& version $=1$ \&_urlVersion $=0$ \&_userid $=5477862 \& m d 5=d d a 25 c 540 a 1722 c$ 10a00dcc22f690a83\&searchtype=a>. Acesso em: 08 abr. 2011. doi: 10.1016/j.postharvbio.2007.11.003.

FERRUA, M.J.; SINGH, R.P. Improved airflow method and packaging system for forced-air cooling of strawberries. International Journal of Refrigeration, Oxford, v.34, n.4 p.1162-1173, 2011 
IBGE. Sistema IBGE de recuperação automática - Sidra 2006. Disponível em: <http//www.sidra.ibge.gov.br>. Acesso em: 01 set. 2011.

KADER, A.A. Postharvest technology of horticultural crops. 3.ed. Davis: Division of Agriculture and Natural Resources, University of California, 2002. 295p.

MALGARIM, M.B. et al. Sistemas e condições de colheita e armazenamento na qualidade de Morangos cv. Camarosa. Revista Brasileira de Fruticultura, Jaboticabal, v.28, n.2, p.185-189, 2006. Disponível em: <http://www.scielo.br/ scielo.php? script = sci_art text\&pid = S 0100 29452006000200007\&lng=pt\&nrm=iso\&tlng=pt $>$. Acesso em: 08 abr. 2011. doi: 10.1590/S0100-29452006000200007.

LADANIYA, M.S. Precooling and refrigeration. In: Citrus fruit: biology, techonology and evaluation. Davis: Division of Agriculture and Natural Resources, University of California, 2008. p.319-331.

MEDINA P.V.L. Manejo pós-colheita de pimentões e pimentas. Informe Agropecuário, Brasília, v.10, n.113, p.72-76, 1984.

PRASANNA, V. et al. Fruit ripening phenomena-an overview. Critical Reviews in Food Science and Nutrition, Воса Raton, v.47, n.1, p.1-19, 2007. Disponível em: <http:// www.informaworld.com/s mpp/section? content $=$ a770814113\&fulltext=713240928>. Acesso em: 08 abr. 2011. doi: 10.1080/10408390600976841.

TALBOT, M.T.; CHAU, K.V. Precooling strawberries. Gainesville: Institute of Food and Agricultural Sciencies, University of Florida, 1991. 8p. (Circular 942).
TALBOT, M.T.; CHAU, K.V. Precooling strawberries agricultural and biological engineering department, florida cooperative extension service. Gainesville: Institute of Food and Agricultural Sciences, University of Florida, 2002. 11p. (Bulletin 942).

TALBOT, M.T.; FLETCHER, J.H. A portable demonstration forced air cooler. Gainesville: Institute of Food and Agricultural Sciencies, University of Florida, 2002. 19p. (Circular 1166).

TERUEL, M.B. et al. Resfriamento de banana-prata com ar forçado. Revista Brasileira de Fruticultura, Jaboticabal, v.24, n.1, p.142-146, 2002. Disponível em: <http:// www.scielo.br/scielo.php?script=sci_arttext\&pid=S010029452002000100031\&lng $=p t \& n r m=i s o \& t \operatorname{lng}=p t>$. Acesso em: 08 abr. 2011. doi: 10.1590/S0100-29452002000100031.

THOMPSON J.F. et al. Room, vacuum, transport, and ice cooling, commercial cooling of fruits, vegetables, and flowers. Davis: Division of Agriculture and Natural Resources, University of California, 1998. 61p. (Publication 21567).

VISSOTTO, F.Z. et al. Pré-resfriamento de produtos-modelo utilizando ar forçado. Brazilian Journal of Food Technology, Campinas, v.3, p.1-10, 2000. Disponível em: <http://www.ital.sp.gov.br/bj/artigos/html/busca/PDF/ v03nu28a.pdf $>$. Acesso em: 08 abr. 2011.

WHITNEY, S.E.C. et al. Roles of cellulose and xyloglucan in determining the mechanical properties of primary cell walls. Plant Physiology, Rockville, v.121, p.657-663. 1999. Disponível em: <http://www.plantphysiol.org/content/121/2/ 657.full>. Acesso em: 08 abr. 2011. doi: 10.1104/pp.121.2.657. 